\title{
Study on the Influence of the National Deep-sea Center Engineering on Hydrodynamics by Numerical Model
}

\author{
Xing Wang ${ }^{1,2}$, Ying Liu ${ }^{1,2, *}$, Xiren Jiang ${ }^{1,2}$, Wenpeng Song ${ }^{1,2}$ and Baolei $\mathrm{Li}^{1}$ \\ ${ }^{1}$ North China Sea Environmental Monitoring Center, State Oceanic Administration, \\ No.22, Fushun Road, Qingdao, China \\ ${ }^{2}$ Shandong Provincial Key Laboratory of Marine Ecology and Environment \& Disaster Prevention and Mitigation, China \\ *Corresponding author
}

\begin{abstract}
A high resolution numerical model of Laoshan Bay is established in order to study the Influence of the National Deepsea Center Engineering on Hydrodynamics. The model is verified by the observation data. The results show that although the hydrodynamic characteristics of the Laoshan Bay did not change, the tide currents near the project change obviously after the construction of the project, and the hydrodynamic environment in the cove significant reduced.
\end{abstract}

Keywords-hydrodynamic; National Deep-sea Center; Laoshan Bay; numerical model; FVCOM

\section{INTRODUCTON}

Qingdao is located in the east coast of China. Surrounded by the sea on three sides, Jiaozhou Bay on west side, Yellow Sea on south side and Laoshan Bay on the east side. It's famous for marine tourism, port and marine science and technology industry. Many Marine scientific research and management organizations in China are located in Qingdao, and National Deep-sea Center is the latest one.

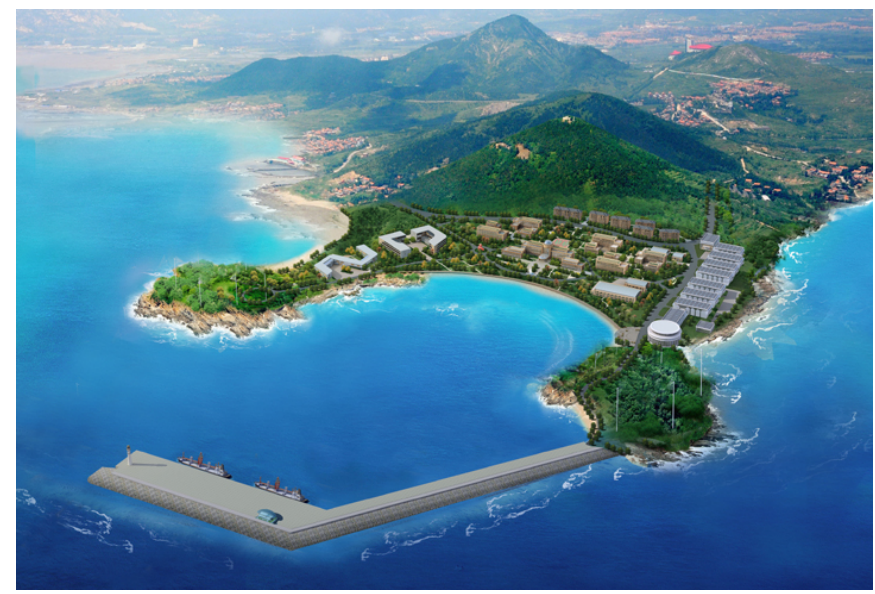

FIGURE I.

GENERAL PLANNING OF THE NATIONAL DEEP-SEA CENTER

National Deep-sea Center is located on the east coast of Qingdao, facing the Laoshan Bay, which is called the blue silicon valley of China. It's the homeport of "Jiao Long" bathyscaphe, it will gather national deep-sea scientific research personnel, and also will become the base of deep-sea equipment and industries [1].

The general planning of NDC (National Deep-sea Center) is shown in Fig. 1, and it shows the design of the wharf and breakwater of this project, which is shown in detail by Fig. 2 . Surrounded by a cove in Laoshan Bay, the oceaneering will change the current in the cove, and may influence on hydrodynamics of the Laoshan bay. A high resolution 3D numerical model is established in order to represent the main dynamics and to study the influence of the project NDC on hydrodynamics [2].

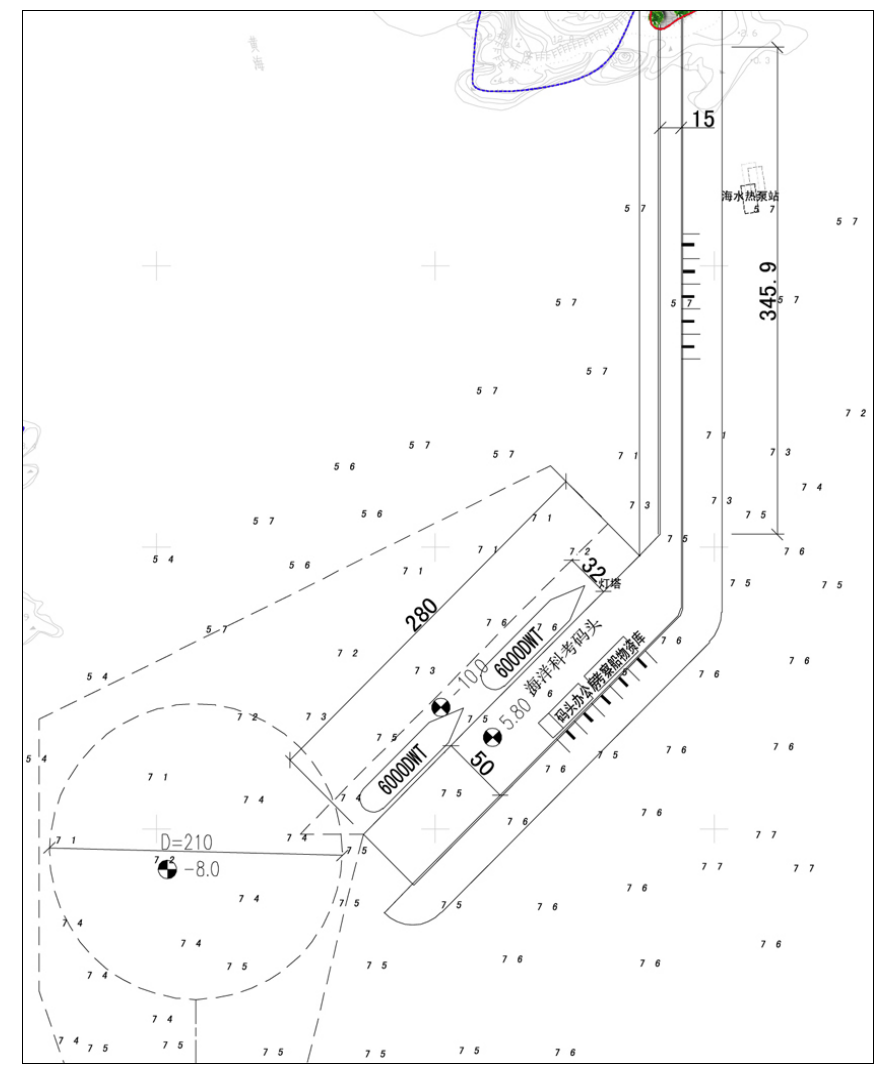

FIGURE II. 2 DESIGN OF THE WHARF AND BREAKWATER 


\section{NUMERICAL MODEL}

The numerical model used in this study is FVCOM: a prognostic, unstructured grid, finite-volume, free-surface, three-dimensional (3D) primitive equation coastal ocean and estuarine model developed by Chen et al. [3]. FVCOM utilizes a modified Mellor and Yamada level 2.5 (MY-2.5) and Smagorinsky turbulent closure schemes for the default setup of vertical and horizontal mixing, respectively [4]. Unlike existing coastal finite-difference and finite-element models, FVCOM solves the hydrostatic primitive equations by calculating fluxes resulting from a discretization of the integral form of these equations on an unstructured triangular mesh. A state-of-theart-transformation is used to represent the vertical coordinate. This approach not only takes advantage of finite-element methods for grid flexibility and finite-difference methods for numerical efficiency but also provides a good numerical representation of momentum, mass, salt, and heat conservation. The detailed description of FVCOM is given in user manual written by Chen et al. [5].

\section{A. Equations}

Under $\sigma$ coordinates:

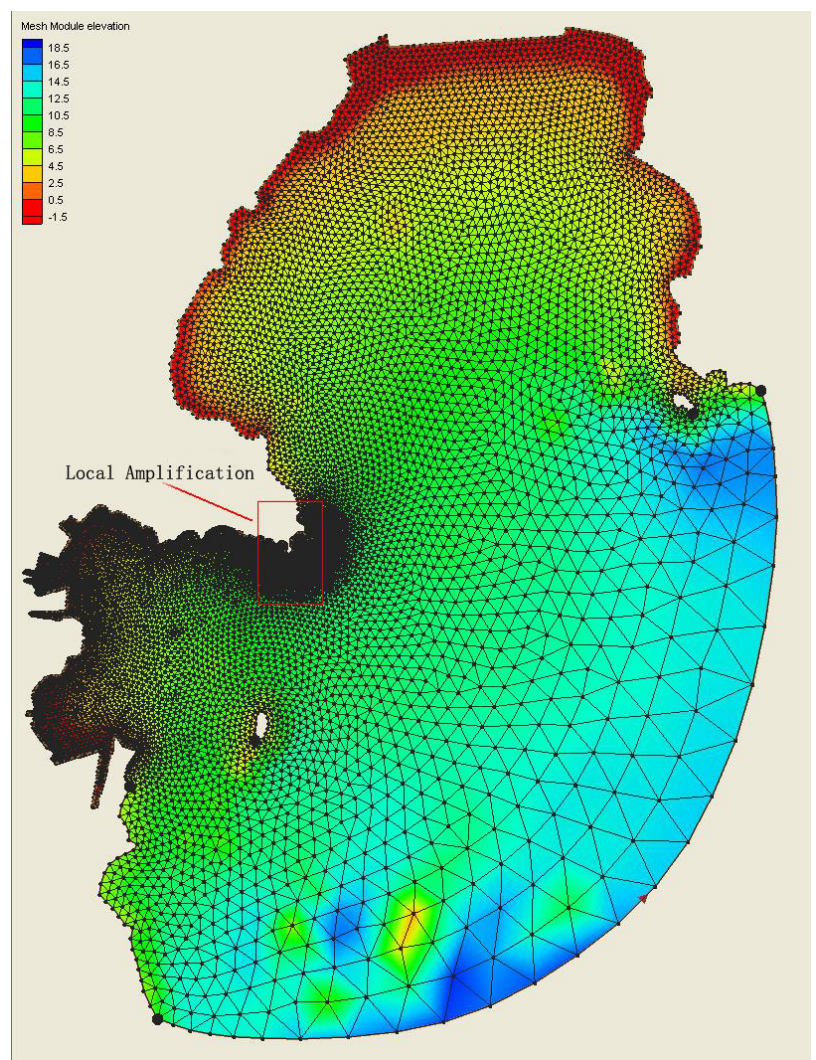

FIGURE III. CONFIGURATION OF THE COMPUTATIONAL MESH

$$
\begin{aligned}
& \frac{\partial u D}{\partial t}+\frac{\partial u^{2} D}{\partial x}+\frac{\partial u v D}{\partial y}+\frac{\partial u \omega}{\partial \sigma}-f v D=-D \frac{\partial}{\partial x}\left(g \eta+p_{\text {atm }}\right)-D \int_{\sigma}^{0}\left(D \frac{\partial \rho}{\partial x}-\sigma \frac{\partial D}{\partial x} \frac{\partial \rho}{\partial \sigma}\right) \mathrm{d} \sigma+\frac{\partial \tau_{x}}{\partial \sigma} \\
& \frac{\partial v D}{\partial t}+\frac{\partial u v D}{\partial x}+\frac{\partial v^{2} D}{\partial y}+\frac{\partial v \omega}{\partial \sigma}+f u D=-D \frac{\partial}{\partial y}\left(g \eta+p_{\text {atm }}\right)-D \int_{\sigma}^{0}\left(\frac{\partial \rho}{\partial y}-\sigma \frac{\partial D}{\partial y} \frac{\partial \rho}{\partial \sigma}\right) \mathrm{d} \sigma+\frac{\partial \tau_{y}}{\partial \sigma} \\
& \frac{\partial P}{\partial z}=-\rho g \\
& \frac{\partial D u}{\partial x}+\frac{\partial D v}{\partial y}+\frac{\partial \omega}{\partial \sigma}+\frac{\partial \eta}{\partial t}=0
\end{aligned}
$$

where $u, v, w$ are the components of the velocity vector in the $x$, $y, \sigma$ directions respectively; $D$ is the water depth; $\eta$ is the free surface; $\rho$ is the specific mass; $P$ is the pressure; $f$ is the Coriolis parameter; $g$ is the gravity acceleration; $g$ is the free surface; $P_{a t m}$ is the atmospheric pressure; $\tau_{\mathrm{x}}, \tau_{\mathrm{y}}$ are the bottom friction term in $x, y$ directions respectively.

\section{B. Grid Resolution}

The computational domain is: East Longitude from $120.64^{\circ}$ to $120.88^{\circ}$, North Latitude from $36.21^{\circ}$ to $36.47^{\circ}$. The horizontal grid mesh is shown in Fig. 3 and Fig. 4, the max resolution is $10 \mathrm{~m}$. Different colors represent different depths in the figures, and the vertical grid is divided into 6 Sigma layers.

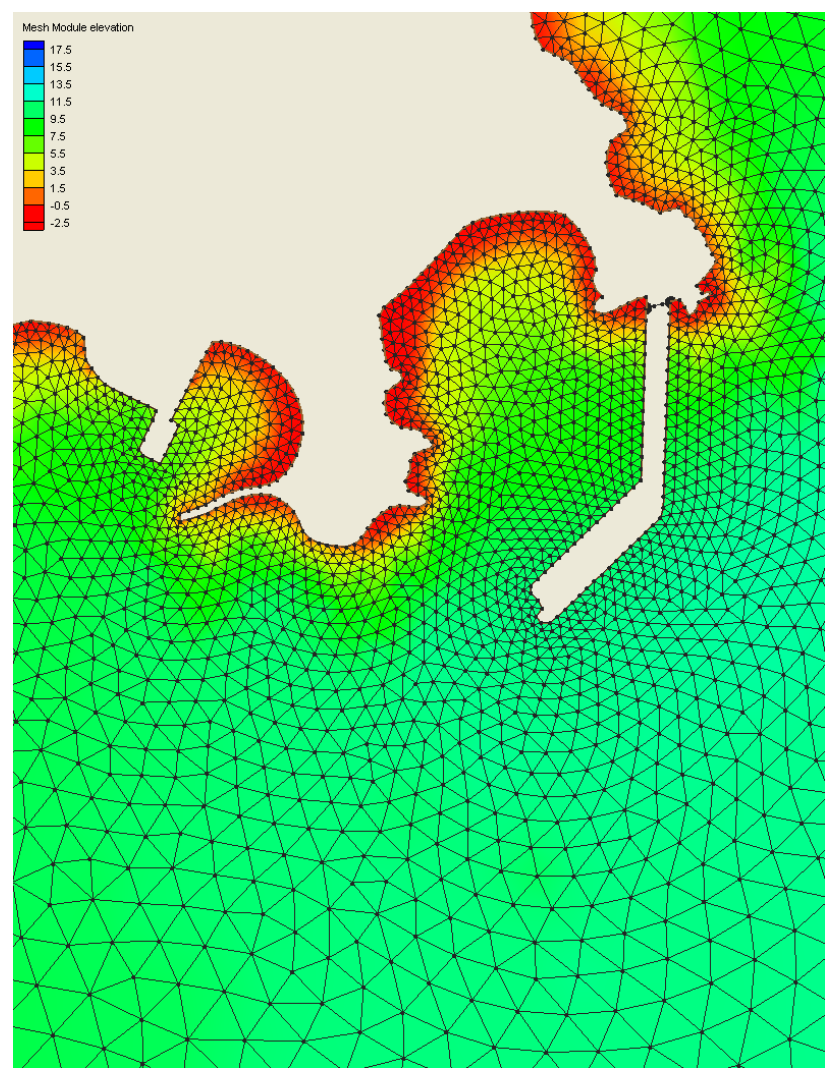

FIGURE IV. CONFIGURATION OF THE MESH GRID NEAR NDC

\section{Boundary and Initial Conditions}
1) Vertical boundary $\omega(0)=\omega(-1)=0$

$$
\begin{aligned}
& \frac{K_{M}}{D}\left(\frac{\partial U}{\partial \sigma}, \frac{\partial V}{\partial \sigma}\right)=-(\langle w u(0)>,<W V(0)>) \quad \sigma \rightarrow 0 \\
& \frac{K_{M}}{D}\left(\frac{\partial U}{\partial \sigma}, \frac{\partial V}{\partial \sigma}\right)=C_{Z}\left(U^{2}+V^{2}\right)^{1 / 2}(U, V) \quad \sigma \rightarrow-1
\end{aligned}
$$


where

$$
\begin{aligned}
& C_{Z}=\operatorname{MAX}\left[\frac{K^{2}}{\left[\ln \left\{\left(1+\sigma_{k b-1}\right) H / Z_{0}\right\}\right]^{2}}, 0.0025\right] \\
& K=0.4 \text { is the Karman constant }
\end{aligned}
$$

\section{2) Horizontal boundary}

The normal velocity at the closed boundary is zero.

The model is forced with the four main tidal components in the area $\mathrm{M}_{2}, \mathrm{~S}_{2}, \mathrm{O}_{1}, \mathrm{k}_{1}$, extracted from the Bohai and Yellow Sea hydrodynamic model's results. The method of water surface elevation series imposed in the open ocean boundary in order to represent the tidal waves is as follows:

$$
\zeta=\sum_{i=1}\left\{f_{i} H_{i} \cos \left[\sigma_{i} t+\left(V_{0 i}+V_{i}\right)-G_{I}\right]\right\}
$$

where $f_{i}, \sigma_{i}$ are the cross factor and angular velocity of the $i$ th tidal component $\left(\mathrm{M}_{2}, \mathrm{~S}_{2}, \mathrm{O}_{1}, \mathrm{~K}_{1}\right)$ respectively, $H_{i}, G_{l}$ are the amplitude and angle of the tidal harmonic constant respectively, $V_{0 i}+V_{i}$ is the tidal argument [6]。

\section{3) Initial conditions}

The initial condition in this model is a cold start solution, the formula is as follows:

$$
\begin{aligned}
& \zeta(x, y, t)_{t=0}=0 \\
& h(x, y, t)_{t=0}=h_{0} \quad(x, y) \\
& u(x, y, t)_{t=0}=0 \\
& v(x, y, t)_{t=0}=0 \\
& w(x, y, t)_{t=0}=0
\end{aligned}
$$

\section{ANALYSIS AND MODEL VALIDATION}

\section{A. Model Validation}

This model is verified by the current observation data at the two stations in the study area in 2006, station A $\left(120^{\circ} 44^{\prime} 25^{\prime \prime} \mathrm{E}\right.$, $\left.36^{\circ} 19^{\prime} 18^{\prime \prime} \mathrm{N}\right)$ was located at about $1 \mathrm{~km}$ southeast from the project, and station $\mathrm{B}\left(120^{\circ} 41^{\prime} 58^{\prime \prime} \mathrm{E}, 36^{\circ} 17^{\prime} 03^{\prime \prime} \mathrm{N}\right)$ was located at about $5 \mathrm{~km}$ southwest from the project. Observation time was from 10a.m. in November 29th to 11:30a.m. in November 30th, observation interval was half an hour.
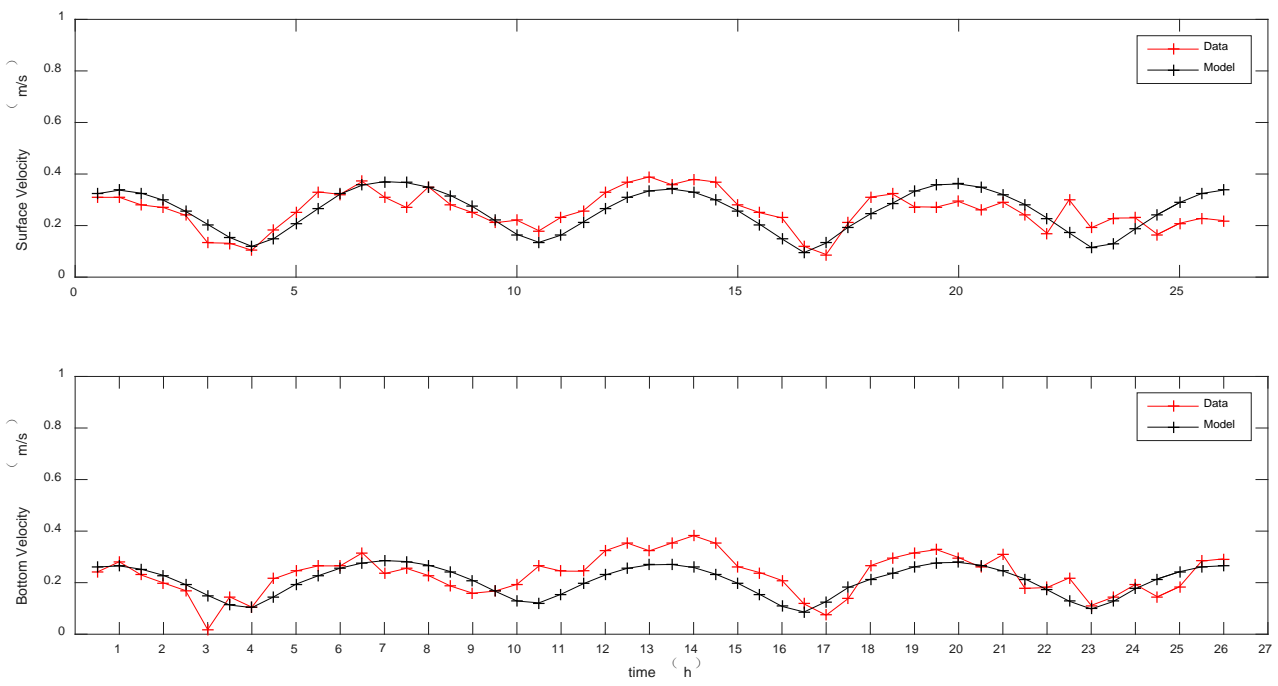

FIGURE V. VERIFICATION OF CURRENT VELOCITY AT STATION A
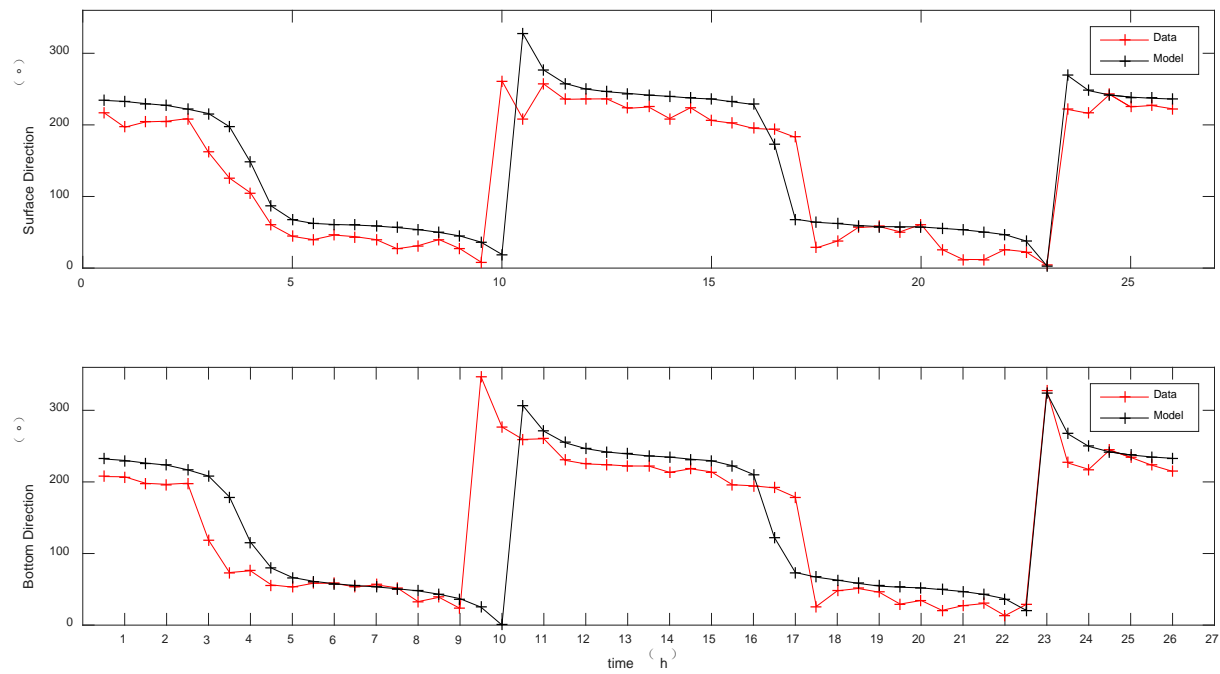

FIGURE VI. VERIFICATION OF CURRENT DIRECTION AT STATION A 
Fig. 5 to Fig. 8 show the comparison between the modeled and observed current time series for all stations. There is a general agreement in current velocity and directions between the modeled and the observed. This reflects that the hydrodynamic model predicted is reliable [7].
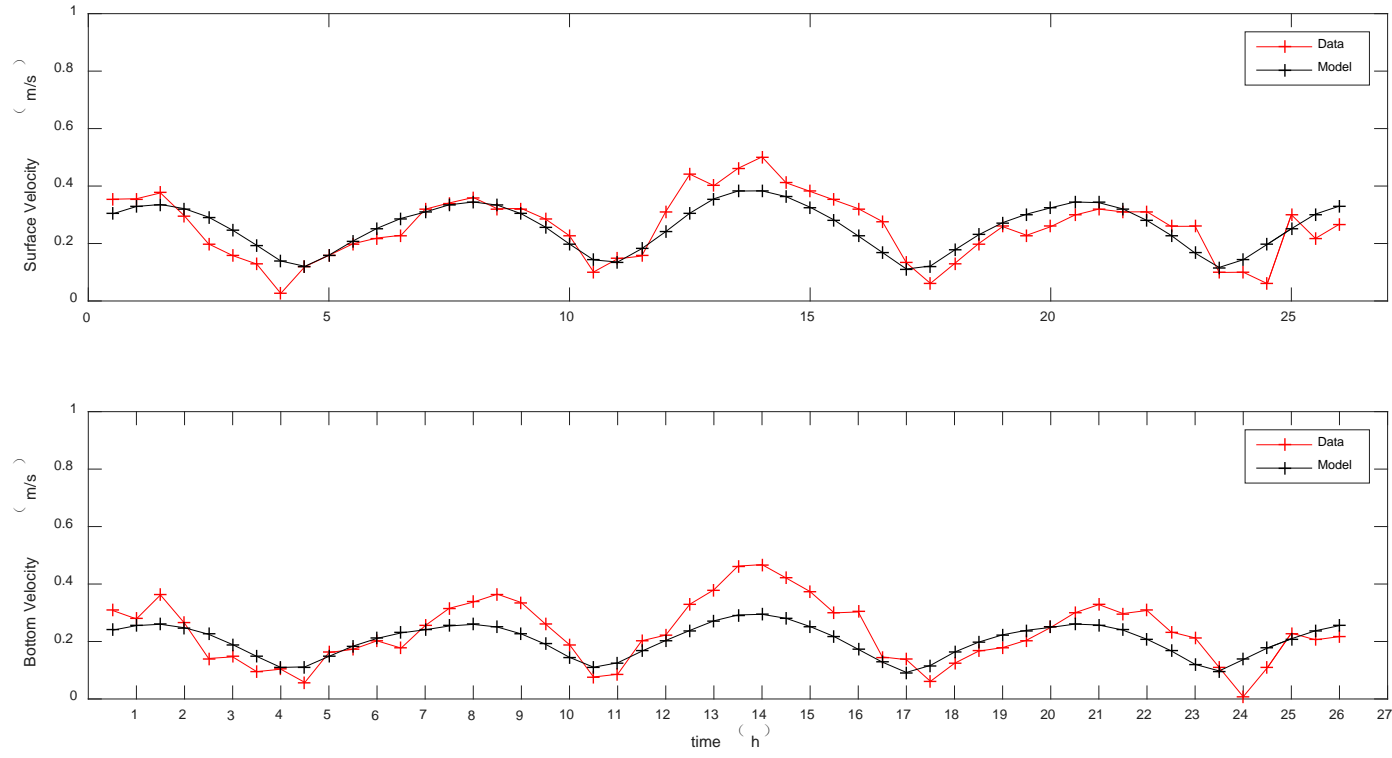

FIGURE VII. VERIFICATION OF CURRENT VELOCITY AT STATION B
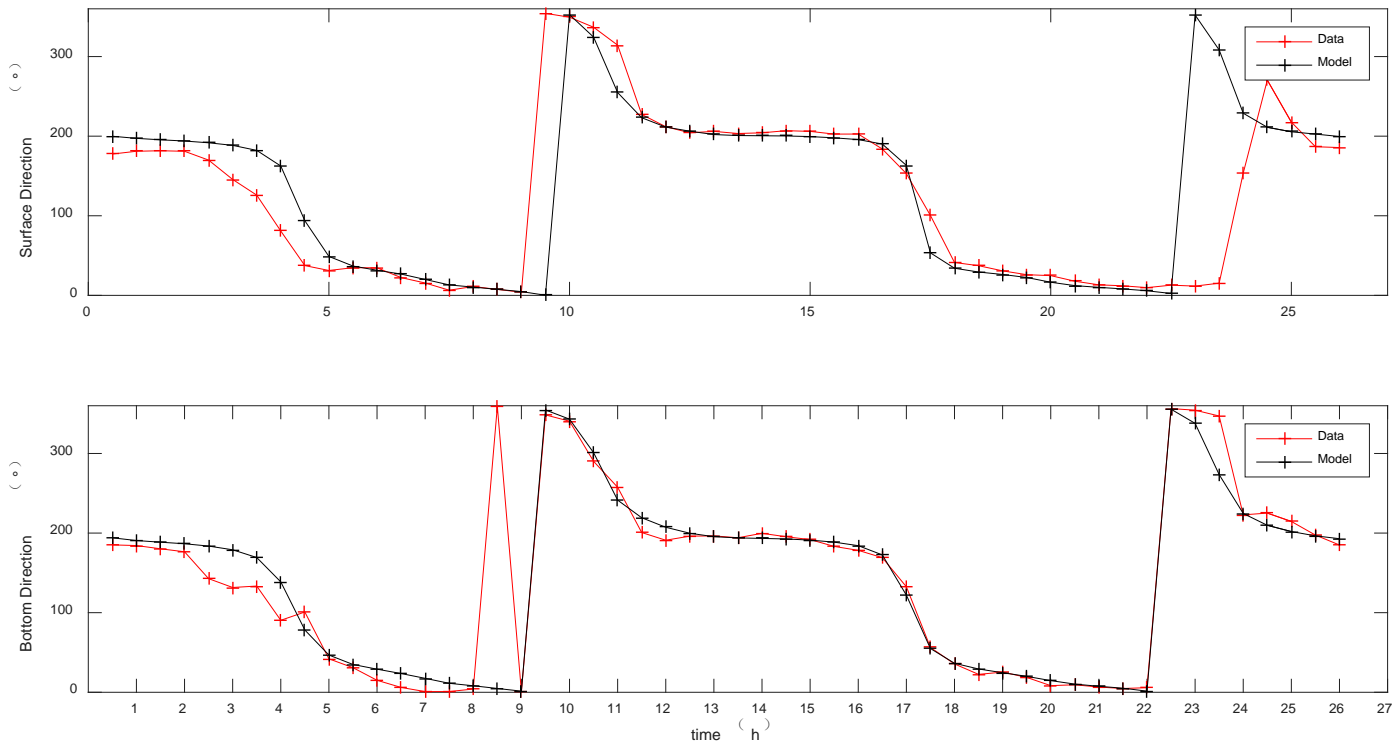

FIGURE VIII. VERIFICATION OF CURRENT DIRECTION AT STATION B

\section{B. Current Analysis}

The validated model helped to study the hydrodynamic characteristic in Laoshan Bay. The local surface flood currents and ebb currents near the engineering are presented in Fig. 9 and Fig. 10 respectively, while the surface flood currents and ebb currents in study area are presented in Fig. 11 and Fig. 12 respectively.

The model results show: the surface velocity is generally $10 \% \sim 30 \%$ larger than the bottom current in Laoshan Bay, the difference between surface current directions and bottom current directions are small. The velocity of flood is slightly larger than the ebb's, whereas the duration between the twoare on the opposite trends. The current velocity is larger in the southeast of Laoshan Bay at flood tide, the maximum velocity can reach $0.8 \mathrm{~m} / \mathrm{s}$; and the currents near the project from west turn to the southwest, the maximum velocity can reach $0.6 \mathrm{~m} / \mathrm{s}$. The maximum current velocity is $0.7 \mathrm{~m} / \mathrm{s}$ at ebb tide, and the currents near the project from northeast turn to the east, the maximum velocity can reach $0.5 \mathrm{~m} / \mathrm{s}$. The currents direction in the study area is almost the opposite while the flood tide and the ebb tide. 


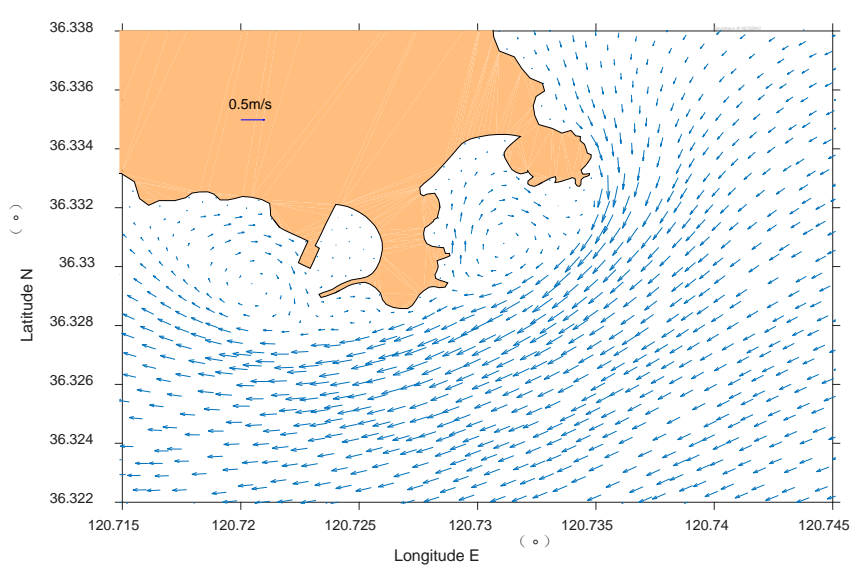

FIGURE IX. SURFACE FLOOD CURRENTS NEAR NDC

\section{INFLUENCE OF ENGINEERING ON HYDRODYNAMIC}

\section{A. Current Field}

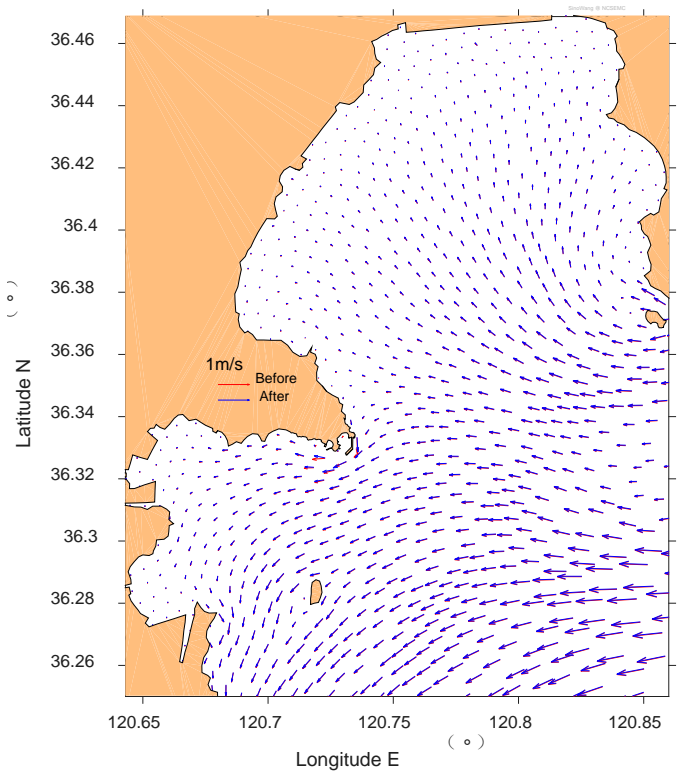

FIGURE XI. COMPARISON OF SURFACE FLOOD CURRENTS IN LAOSHAN BAY

Through the analysis of model results, the hydrodynamic characteristics of the Laoshan Bay did not change mainly. The surface flood current field and ebb current field of study area are presented in Fig. 11 and Fig. 12 respectively. The red arrows indicate the currents before the construction of project NDC, and the blues indicate the currents after the construction of project NDC. The marine engineering shows little influence on the current field of the large study area.

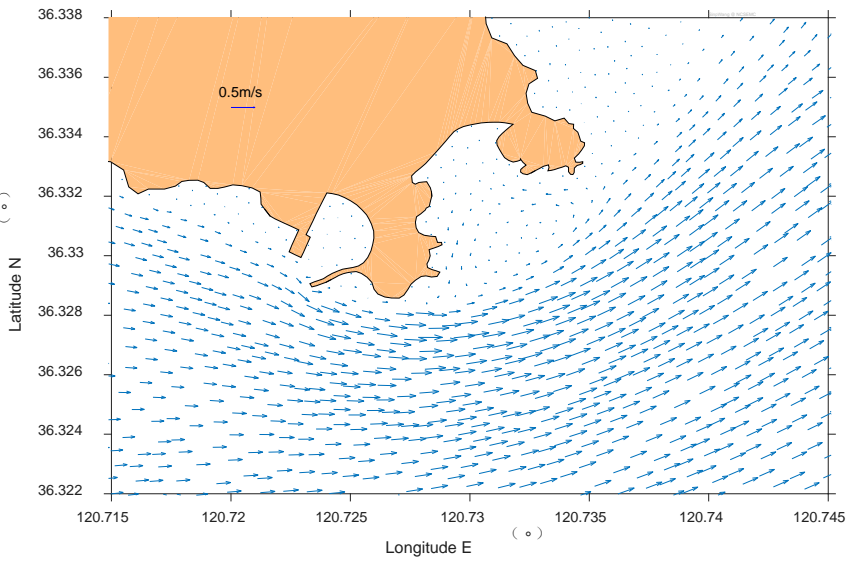

FIGURE X. SURFACE EBB CURRENTS NEAR NDC

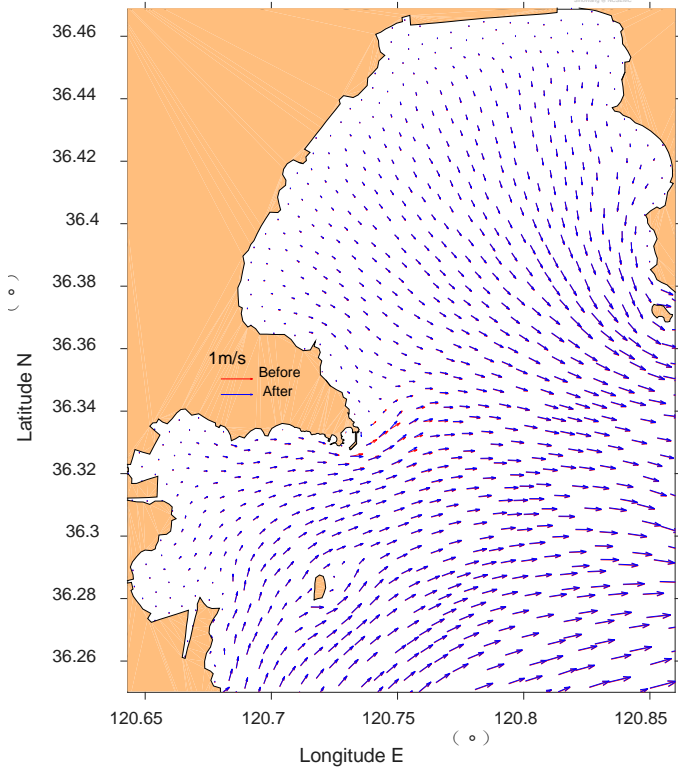

FIGURE XII. COMPARISON OF SURFACE EBB CURRENTS IN LAOSHAN BAY

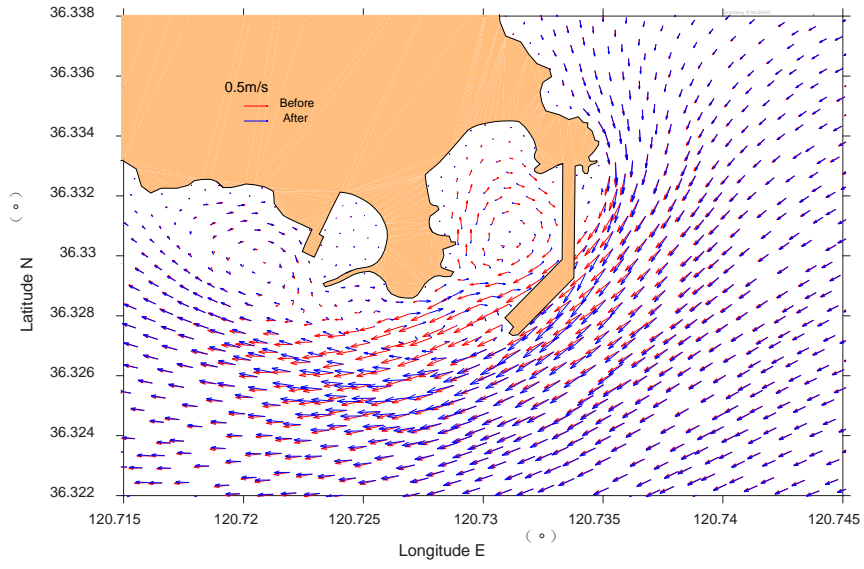

FIGURE XIII. COMPARISON OF SURFACE FLOOD CURRENTS NEAR NDC 


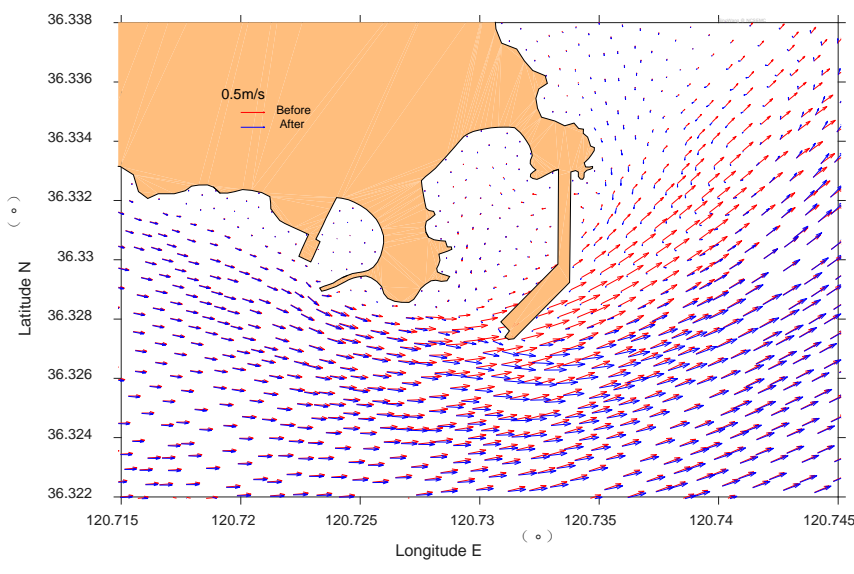

FIGURE XIV. COMPARISON OF SURFACE EBB CURRENTS NEAR NDC

The local surface flood current field and ebb current field near the project are presented in Fig. 13 and Fig. 14 respectively. Those show the current field near project changes significantly, but only within a range of $2 \mathrm{~km}$ around the project. Due to the influence of marine engineering, the current changes more obviously in the west area of the project at flood tide while it changes more obviously in the east area of the project at ebb tide. The vortex intensity is much reduced and its direction is reversed in the cove at flood tide.

\section{B. Current of Representative Points}

In order to study the characteristics of the current field near NDC and the hydrodynamic changes before and after the construction of the project, 10 representative points were chose in the sea area near the breakwater and wharf [8]. The locations of 10 points are show in Fig. 15.

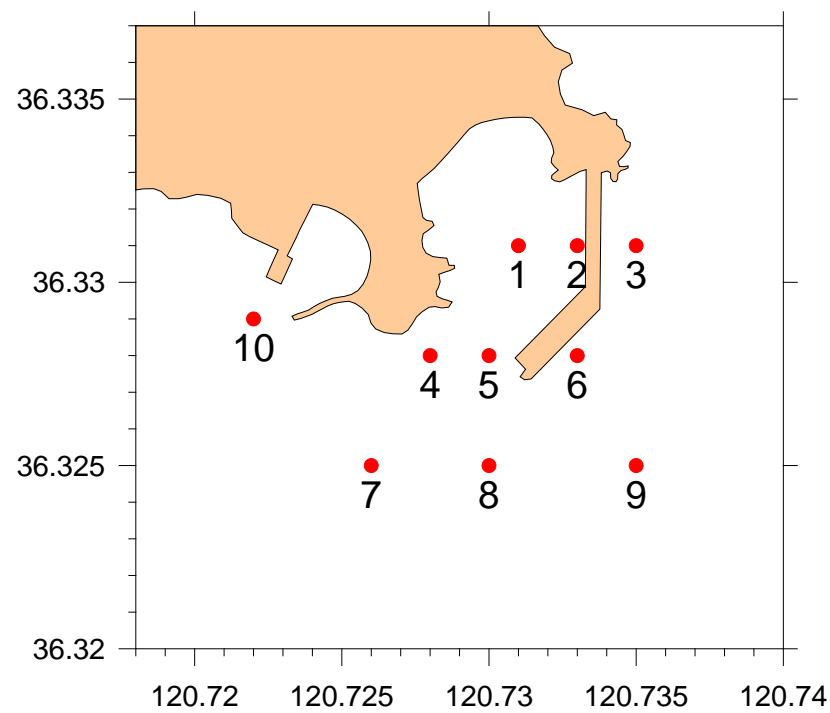

FIGURE XV. LOCATIONS OF REPRESENTATIVE POINTS

The hydrodynamic environment in the cove $(1 \#, 2 \#, 4 \#, 5 \#)$ is much reduced, while outside of the cove, most points currents are enhanced at flood tide and reduced at ebb tide. See table 1 and table 2 for more details.

The abbreviations in the table are as follows, FD: flood tide, EB: ebb tide, LY: layer, PN: point, BN: before the construction of NDC, AN: after the construction of NDC, SF: surface, BM: bottom, CV: current velocity, CD: current direction, CC: current change, SV: surface velocity, BV: bottom velocity, SD: surface current direction, $\mathrm{BD}$ : bottom current direction, $\mathrm{AB}$ : absolute, RP: relative percentage.

TABLE I. VARIATIONS OF CURRENT VELOCITY (CM/S) AND DIRECTION $\left({ }^{\circ}\right.$ ) AT FLOOD TIDE

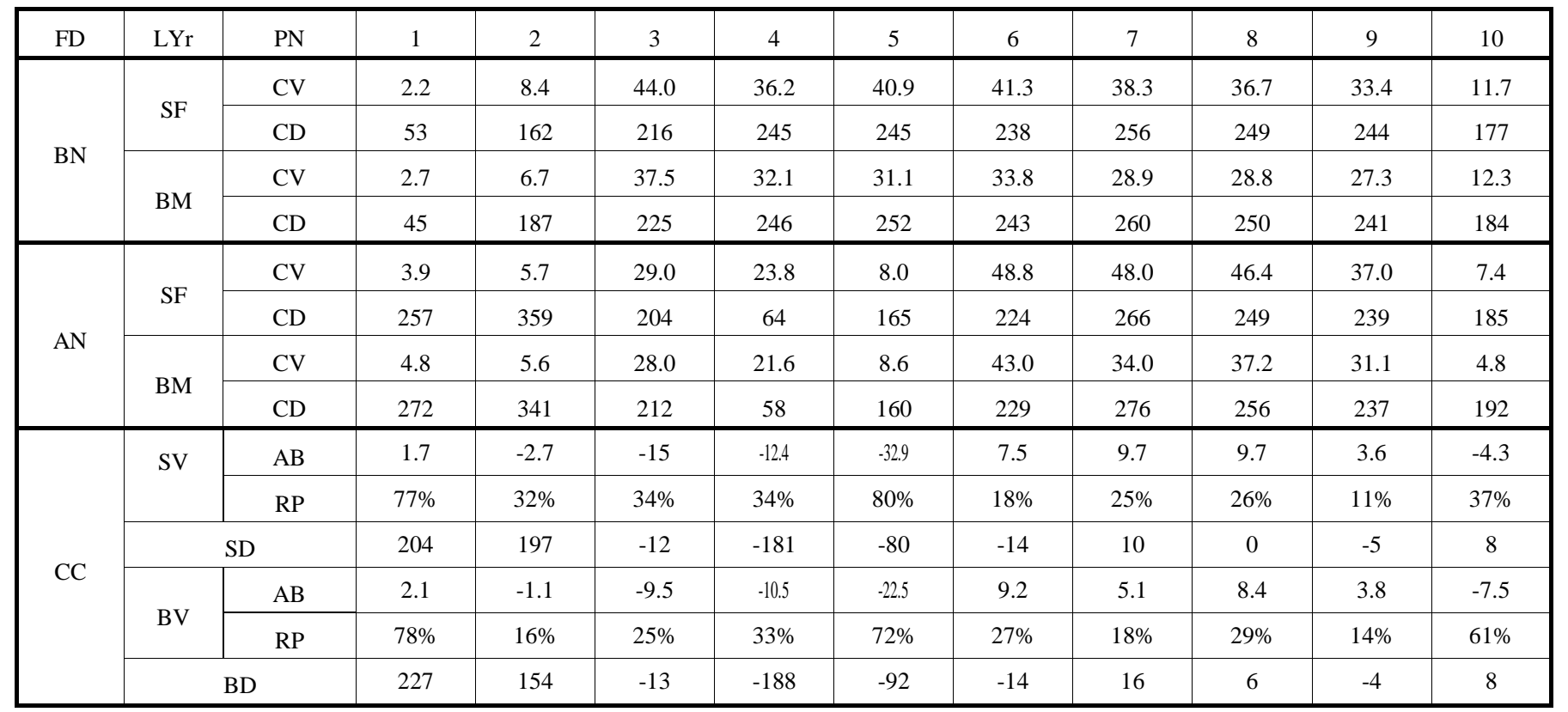


TABLE II. VARIATIONS OF CURRENT VELOCITY (CM/S) AND DIRECTION $\left(^{\circ}\right.$ ) AT EBB TIDE

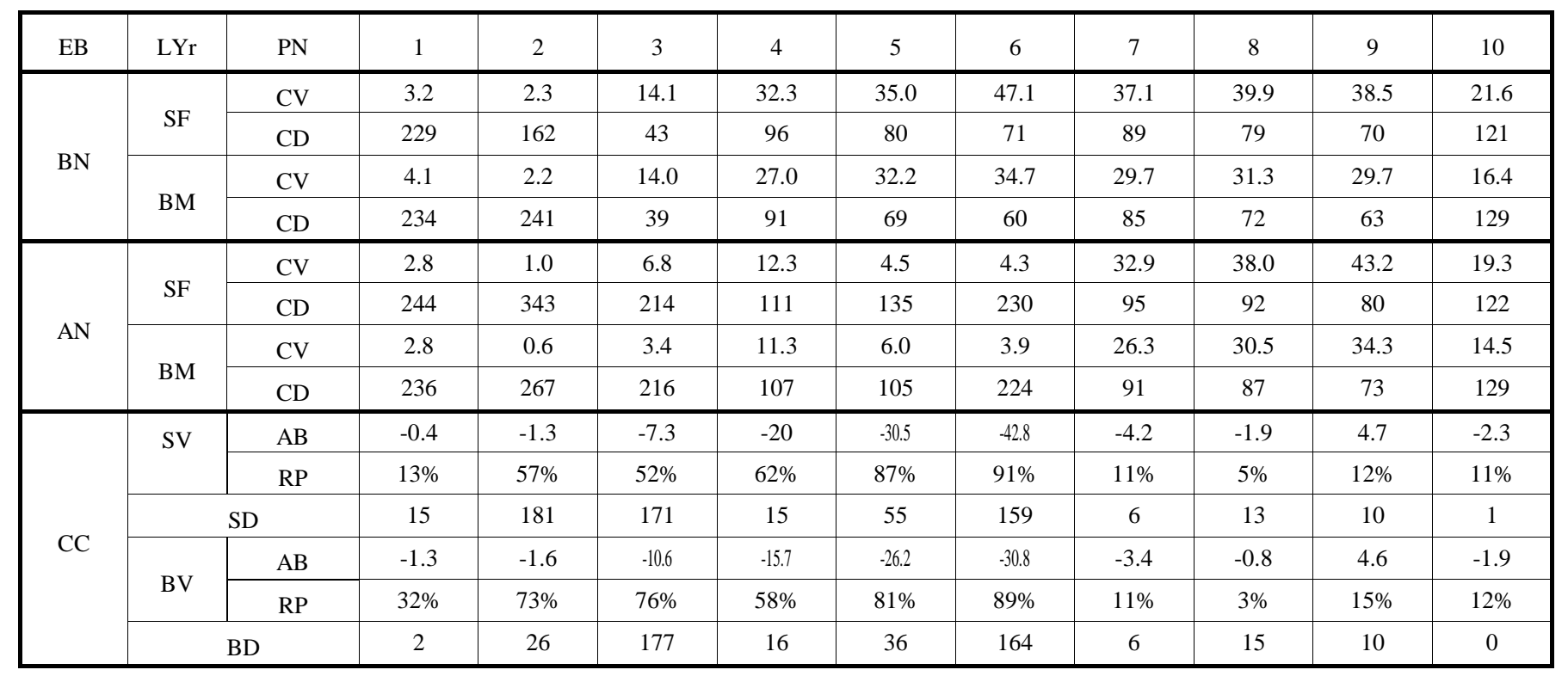

Flood, On the surface layer, currents velocity on locations of $2 \#, 3 \#, 4 \#, 5 \#$ and $10 \#$ is decreased, while it increased on $1 \#$, $6 \#, 7 \#, 8 \#$ and 9\#. Currents change more than $10 \mathrm{~cm} / \mathrm{s}$ on $3 \# 4 \#$ and $5 \#$, and the maximum reduction is $32.9 \mathrm{~cm} / \mathrm{s}$ on $5 \#$. On the bottom layer, similarly to the surface layer, currents on $2 \#, 3 \#$, $4 \#, 5 \#$ and $10 \#$ are decreased, and increased on the last 5 points. The current variation ranges are more than $10 \mathrm{~cm} / \mathrm{s}$ on $4 \#$ and $5 \#$, and the maximum reduction is $22.5 \mathrm{~cm} / \mathrm{s}$ on $5 \#$.

Ebb , On the surface layer, current velocity increased on locations of 9\#, while it decreased on other 9 points. Currents decrease more than $10 \mathrm{~cm} / \mathrm{s}$ on $4 \#$, $5 \#$ and $6 \#$, and the maximum reduction is $42.8 \mathrm{~cm} / \mathrm{s}$ on $6 \#$. On the bottom layer, similar to surface, current on $9 \#$ is increased, and others 9 points are decreased, currents on $3 \#, 4 \#, 5 \#$ and 6\# decreased over $10 \mathrm{~cm} / \mathrm{s}$, and the maximum reduction is $30.8 \mathrm{~cm} / \mathrm{s}$ on $6 \#$.

\section{CONCLUSION}

A high resolution 3D numerical model is established to study the influence of NDC on hydrodynamics. Based on the comparison of the hydrodynamic simulation results before and after the construction of the marine engineering, the conclusions are as follow.

The hydrodynamic characteristics of the Laoshan Bay did not change mainly after the construction of the project NDC. The marine engineering shows little influence on the current field of the large study area, but the local current field near the project changes obviously.

The construction of National Deep-sea Center shows a significant influence on the local current field. The tide currents near the project change obviously, the maximum current velocity changes more than $40 \mathrm{~cm} / \mathrm{s}$, and the hydrodynamic environment in the cove reduced significantly.

The change of hydrodynamic force will lead to the change of sediment erosion and accumulation. The northeastern sand beach and the northern pebble beach in the cove may be damaged in long term influence of the project. We should pay more attention to the marine environment near this project in the future.

\section{ACKNOWLEDGMENT}

This work was supported by National Key R\&D Plan (No. 2016YFC1402404-02).

\section{REFERENCES}

[1] Mingyi Chen, The New Home of "Jiao Long" - An Interview with the National Deep-sea Center, StraitsScience, 2016, 03, pp.59-60. (in Chinese with English abstract)

[2] M. Fossati, I. Piedra-Cueva, A 3D hydrodynamic numerical model of the Río de la Plata and Montevideo's coastal zone, Applied Mathematical Modelling, 2013, 37, pp. 1310-1332.

[3] Chen, C., H. Liu, and R. Beardsley, An unstructured grid, finitevolume, three-dimensional, primitive equations ocean model: Application to coastal ocean and estuaries, J. Atmos. Ocean Technol., 2003, 20(1), pp. 159-186.

[4] Mellor, G. L., and T. Yamada, Development of a turbulence closure model for geophysical fluid problem, Rev. Geophys., 1982, 20, pp. 851875.

[5] Chen, C., G. Cowles, and R. C. Beardsley, An unstructured grid, finitevolume coastal ocean model: FVCOM user manual, SMAST/UMASSD Tech. Rep., 04-0601, 2009, pp. 183.

[6] Jianqiang. Liu, and Linna Ma, Numerical study on the influence of port construction on hydrodynamic environment in Laizhou Bay, Ocean Development and Mamagement, 2014, 4, pp. 77- 81. (in Chinese)

[7] G. M. Jahid Hasan, and Dirk Sebastiaan van Maren, Hydrodynamic modeling of Singapore's coastal waters-Nesting and model accuracy, Ocean Modelling, 2016, 97, pp. 141- 151.

[8] Yuwu Jiang, and Qinhua Fang, The effect evaluation of coastal engineering to hydrodynamics, Journal of Xiamen University (Natural Science), Vol. 43, 2004, 8, pp. 77- 81. (in Chinese with English abstract) 